\title{
ANÁLISE MULTITEMPORAL DA DINÂMICA DA PAISAGEM NA BACIA HIDROGRÁFICA DO RIO TOCANTINZINHO - GOIÁS
}

\author{
Rosane Borges de Oliveira \\ Universidade Federal de Goiás (UFG) \\ Instituto de Estudos Sócio Ambientais, Goiânia, GO, Brasil \\ rosaneborgesoliveira@gmail.com \\ Karla Maria Silva de Faria \\ Universidade Federal de Goiás (UFG) \\ Instituto de Estudos Sócio Ambientais, Goiânia, GO, Brasil \\ karla faria@ufg.br
}

\section{RESUMO}

O processo histórico de desmatamento do cerrado no último século foi direcionado para a região norte do bioma, que concentrava os maiores fragmentos vegetacionais, áreas protegidas e as prioritárias para conservação da biodiversidade. Essa pressão antrópica demanda estudos que avaliem a configuração estrutural do processo de fragmentação no entorno das áreas protegidas. A bacia hidrográfica do rio Tocantinzinho se insere nesse cenário e foi selecionda para avaliação das mudanças na estrutura da paisagem considerando dados históricos de cobertura e uso da terra, para identificar padrões espaçotemporais que possam influir no funcionamento da paisagem. Foram classificadas imagens de satélite (LANDSAT) entre 1985 e 2016, com aplicação de índices descritores da paisagem que, permitiram comparação espacial em sucessão histórica para área da bacia. Os resultados indicam que a substituição das manchas de vegetação nativa por manchas antrópicas impactaram principalmente a formação campestre e que o processo de antropização da área é recente com evidências de desenvolvimento a partir dos anos 2000; verifica-se que as pastagens já estão sendo substituídas pela agricultura e que o processo de fragmentação afetou o tamanho e conectividade das formações vegetacionais, o que pode afetar diretamente as áreas protegidas situadas dentro e no entorno e da bacia hidrográfica.

Palavras-chave: Métricas da paisagem. Ecologia da Paisagem. Mudança de uso da terra. Fragmentação da paisagem.

\section{MULTITEMPORAL ANALYSIS OF THE DYNAMICS OF THE LANDSCAPE IN THE HYDROGRAPHIC BASIN OF THE TOCANTINZINHO RIVER - GOIÁS}

\begin{abstract}
The historical process of deforestation of the cerrado in the last century was directed to the northern region of the biome, which concentrated the largest vegetation fragments, protected areas and priority areas for biodiversity conservation. This anthropic pressure demands studies that assess the structural configuration of the fragmentation process around protected areas. The Tocantinzinho River basin fits into this scenario and was selected to assess changes in the landscape structure considering historical data on land cover and use, to identify space-time patterns that may influence the functioning of the landscape. Satellite images (LANDSAT) were classified between 1985 and 2016, with the application of landscape descriptive indexes, which allowed spatial comparison in historical succession for the basin area. The results indicate that the replacement of patches of native vegetation by anthropic patches mainly impacted the grassy field vegetation and that the process of anthropization of the area is recent with evidence of development from the 2000s; ensure that the pastures are already being replaced by agriculture and that the fragmentation process has affected the size and connectivity of vegetation formations, which can directly affect the protected areas located in and around the river basin.
\end{abstract}

Keywords: Landscape metrics. Landscape Ecology. Land use change. Fragmentation of the landscape.

\section{INTRODUÇÃO}

A substituição de habitats naturais por áreas de cultivo de grãos e formação de pastagens extensivas no Cerrado se destaca por ameaçar de extinção diversas espécies animais e vegetais. Em 2013,

$\begin{array}{lllll}\text { Caminhos de Geografia } \quad \text { Uberlândia-MG } & \text { v. 22, n. } 81 \quad \text { jun./2021 } & \text { p. 74-87 } & \text { Página } 74\end{array}$


áreas de uso antrópico neste bioma somavam $41 \%$, das quais $29,5 \%$ ocupadas por pastagem plantada e $11,6 \%$ destinadas à agricultura (MMA, 2015). Dados mais recentes do projeto Mapbiomas (2019) indicam que a vegtação nativa correspondem a $54 \%$ da área total do bioma, com a agropecuária representanto $43 \%$ de área. A perda líquida da vegetação original do cerrado entre 1984 e 2018 é de 24\%, o que evidencia a conversão da cobertura vegetal nativa para áreas de produção de commodities agropecuárias.

A perda de biodiversidade suscita preocupação ambiental e econômica por impactar a capacidade dos ecossistemas de sustentar serviços ecológicos essenciais à qualidade de vida da sociedade humana, como, por exemplo, controle de pragas, ciclagem de nutrientes, fertilidade do solo e autodepuração da água.

O reconhecimento da abundância de espécies edêmicas no Cerrado e da existência de pressões e emeaças decorrentes da perda de habitats faz desse bioma uma área prioritária para conservação, com proposição de ampla distribuição de unidades de conservação sob a responsabilidade de distintos agentes publicos (federal, estadual e municipal), assim como privado, que se conectam em mosaico de áreas protegidas ou em áreas internacionais prioritárias para conservação da biodiversidade, como as reservas da Biosfera.

Nesse contexto, a bacia hidrográfica do rio Tocantinzinho se destaca como objeto de estudo por compreender áreas ainda consideradas como mais conservadas do Cerrado goiano, alvos de diversas políticas públicas para conservação da biodiversidade.

A importância da conservação da vetação nativa na bacia é ressaltada em virtude de constituir potenciais corredores ecológicos, que podem integrar áreas de unidades de conservação, e essenciais ao equilíbrio de processos morfogenéticos em áreas de declives acentuados, controlando a ocorrência de processos erosivos e o carreamento de sedimentos que podem afetar a quantidade e qualidade dos recursos hídricos.

De modo geral, mudanças de cobertura e uso da terra podem influenciar a estrutura e o funcionamento dos ecossistemas por décadas e até séculos após essas atividades cessarem, e conhecer o padrão dessas mudanças possibilita a interpretação de processos paisagísticos para identificação de metas e de ferramentas apropriadas para atingir objetivos de planejamento e gestão das paisagens (FOSTER et al., 2003).

Dentre as várias metodologias para análise da influência aos ecossistemas e as paisagens, Metzger (2001) e Valente, (2001), indicam que a abordagem da Ecologia da Paisagem ao inserir o homem no seu sistema de análise, incorpora componentes culturais aos naturais e permite quantificar a estrutura da paisagem, potencializando a análise de problemas ambientais que envolvem mudanças nas funções dos ecossistemas.

A abordagem metodológica da ecologia da paisagem ao avaliar descritivamente as mudanças de uso do solo com índices descritores da paisagem contribui para avaliação da configuração histórica da paisagem podendo contribuir com indicadores para planejamento de áreas de alta relevância ambiental.

Assim, o presente trabalho objetiva analisar mudanças na estrutura da paisagem na bacia hidrográfica do rio Tocantinzinho (BHRT) considerando dados históricos de cobertura e uso da terra, de modo a identificar padrões espaço-temporais que possam influir no funcionamento da paisagem, com base na abordagem da Ecologia da Paisagem.

\section{MATERIAIS E MÉTODOS}

\section{Área de pesquisa}

A BHRT, além de unidade integradora, abrange parcialmente importantes áreas prioritárias para conservação do Cerrado e da sua biodiversidade. Entre estas áreas estão o Parque Nacional da Chapada dos Veadeiros (PNCV), a Área de Proteção Ambiental (APA) do Pouso Alto, a Reserva da Biosfera do Cerrado (Fase II) que compreendem um mosaico de Unidades de Conservação (UCs) e o 
Corredor Ecológico Paranã-Pireneus, além de polígonos definidos pelo Projeto de Identificação de Áreas Prioritárias para a Conservação da Biodiversidade em Goiás (PDIAP) (Figura 1).

Figura 1 - Localização da BHRT no estado de Goiás.

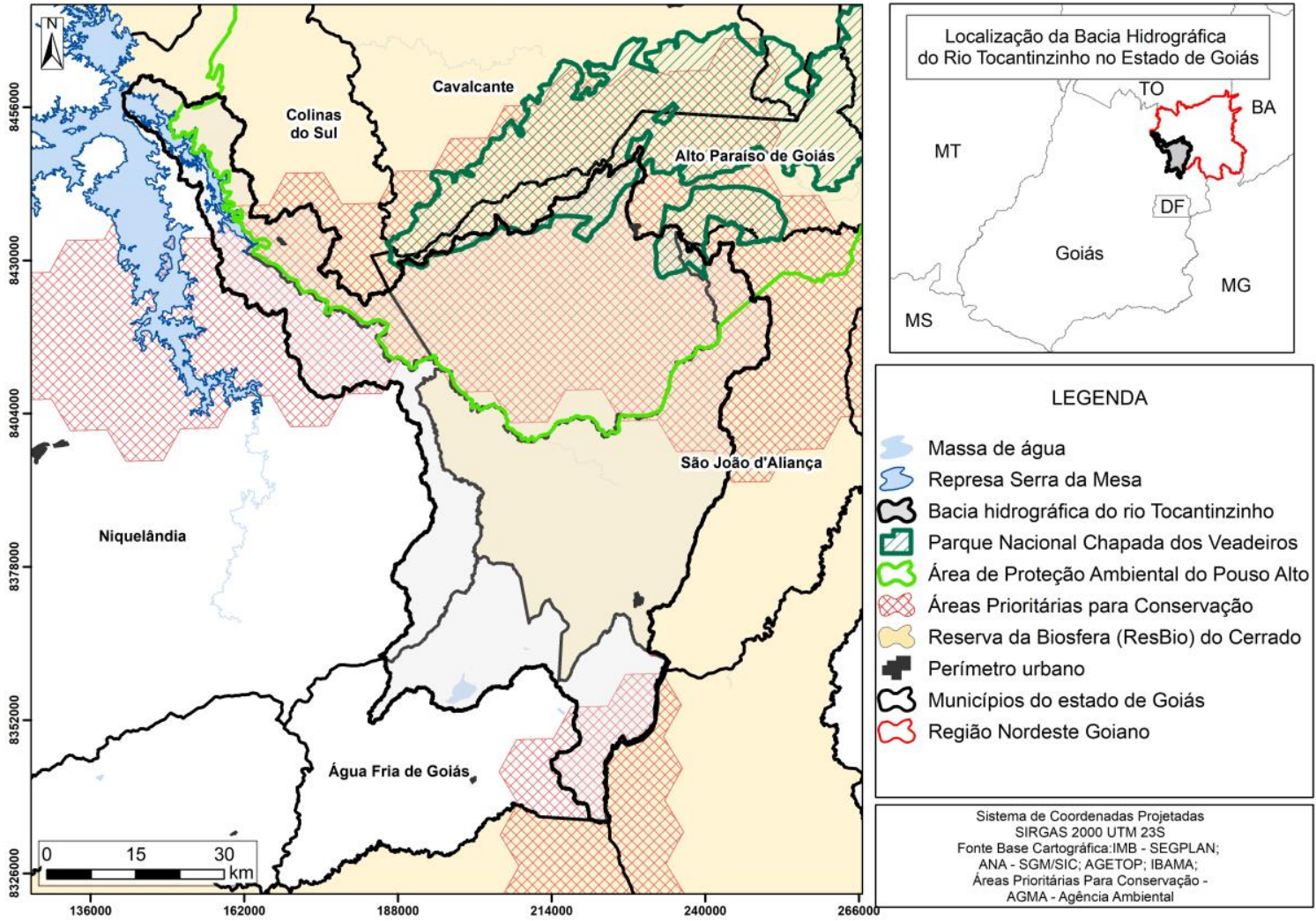

Fonte - Organização das autoras.

A BHRT se localiza predominantemente na região Nordeste Goiano, abrangendo parcialmente os municípios Alto Paraíso de Goiás $(30,04 \%$ da área total da bacia), São João d'Aliança $(32,06 \%)$, Colinas do Sul (8,87\%), Niquelândia (14,21\%) e Água Fria de Goiás (14,79\%).

A região, apesar de apresentar sobreposição de diversas políticas de conservação, se insere no cenário de crescente pressão antrópica sobre os remanescentes de vegetação nativa observado nos últimos anos no estado de Goiás.

Dados do Prodes Cerrado (Projeto Monitoramento Cerrado), recortados para regiões de planejamento do estado de Goiás, indicam que o Norte Goiano, onde situa-se Niquelândia, é a região que mais desmatou entre 2008 e 2017; o Nordeste Goiano, onde localizam-se Colinas do Sul, Alto Paraíso e São João D'Aliança, acumulou a segunda maior taxa de desmatamento; já a região Entorno do Distrito Federal, onde se localiza Água Fria de Goiás, é a terceira região do estado que mais desmatou (RIBEIRO et al., 2019). As taxas de desmatamento, de acordo com estes autores, são de $29,49 \%, 17,61 \%$ e $14,14 \%$, respectivamente.

Este comportamento de desmatamento dos municipios integrantes da bacia reforça a necessidade de avaliação do comportamento da dinâmica e da estrutura da paisagem da BHRT, que como apresentado tem alta relevância ambiental para manutenção das unidades de conservação existentes na região. $E$ como os aspectos topográficos (predomínio de declividades entre 0 a 12\%) favorecem a ocupação de atividades agropecuárias em mais de $50 \%$ da área, a bacia é marcada pela existência na porção noroeste de forte a muito forte dissecação que limita processos de ocupação e favorece a seleção de áreas para conservação. 


\section{Análise da cobertura e uso da terra}

Para análise da dinâmica da paisagem na BHRT, inicialmente procedeu-se com a classificação de imagens Landsat dos anos 1985, 1995, 2005 e 2016 a fim de mapear a cobertura e uso da terra. Foram utilizadas as cenas $221 / 70$ do satélite Landsat $5 / \mathrm{TM}$ e $8 / \mathrm{OLI}$, com resolução espacial de 30 metros. As imagens datadas de 16/07/1985, 28/07/1995 e 07/07/2005 e 03/06/2016 foram adquiridas já ortorretificadas no portal USGS Earth Explorer.

As imagens foram classificadas no Spring, na forma supervisionada pixel a pixel, com o classificador Maxverossimilhança e limiar de aceitação de 99,9\%, a partir das composições RGB 543 (Landsat 5) e RGB 654 (Landsat 8), previamente manipuladas no ENVI.

A aquisição de amostras para a classificação baseou-se no padrão de resposta espectral de cada classe, considerando a chave de interpretação adaptada de Faria (2011) e Ponciano (2017). Foram consideradas as classes de cobertura vegetal, conforme proposta de Ribeiro e Walter (2008), em nível de formação, sendo elas florestal, savânica e campestre, e classes de agricultura, pastagem, solo exposto, área queimada, área urbanizada, estrada e água, relacionadas ao uso da terra (Quadro 1).

Quadro 1 - Caracterização das classes de cobertura e uso da terra mapeadas.

\begin{tabular}{|c|c|}
\hline Cobertura e uso mapeada & Caracterização \\
\hline Formação Florestal & $\begin{array}{l}\text { As Matas de Galeria e Matas Ciliares compõem, juntamente com o Cerradão e a } \\
\text { Mata Seca, a formação florestal. A Mata Ciliar acompanha os rios de médio e } \\
\text { grande porte, já a Mata de Galeria acompanha rios de pequeno porte formando } \\
\text { galerias. A Mata Seca não possui associação com cursos de água e se } \\
\text { caracteriza por apresentar diversos níveis de caducifolia durante estação seca e } \\
\text { por ocorrer nos interflúvios. O Cerradão caracteriza-se pela presença de } \\
\text { espécies que ocorrem no Cerrado sentido restrito e de espécies que ocorrem na } \\
\text { formação florestal. }\end{array}$ \\
\hline Formação Campestre & $\begin{array}{l}\text { Caracteriza-se pela ausência de árvores na paisagem, havendo predomínio de } \\
\text { arbustos e subarbustos entremeados no estrato arbustivo-herbáceo, encontrados } \\
\text { em solos rasos, como Neossolos, Cambissolos ou Plintossolos Pétricos. }\end{array}$ \\
\hline Formação Savânica & $\begin{array}{l}\text { Caracteriza-se pela ocorrência de árvores e arbustos espalhados sobre o estrato } \\
\text { graminoso. Abrange o Cerrado sentido restrito, caracterizado pela presença de } \\
\text { árvores baixas e tortuosas e com ramificações retorcidas, representado pelas } \\
\text { fitofisionomias do Cerrado Denso, Típico, Ralo e Rupestre, e parte das } \\
\text { fitofisionomias consideradas do Cerrado sensu lato, a saber: Vereda, Parque de } \\
\text { Cerrado e Palmeiral. }\end{array}$ \\
\hline Agricultura & Áreas agrícolas, incluindo as pastagens plantadas. \\
\hline Pastagem & Áreas de pastagem natural, com uso vegetação nativa. \\
\hline Solo Exposto & $\begin{array}{l}\text { Áreas de estradas vicinais e áreas de solo nu naturais em meio ao dossel aberto } \\
\text { da vegetação ou áreas de solo nu que evidenciam áreas de pastagem } \\
\text { degradada. }\end{array}$ \\
\hline Área Queimada & Cicatrizes de queimadas. \\
\hline Estrada & Vias principais: GO 132, GO 239 e GO 119. \\
\hline Água & $\begin{array}{l}\text { Cursos d'água representadas pela presença de rios, lagos, } \\
\text { barramentos/reservatórios artificiais etc. }\end{array}$ \\
\hline
\end{tabular}

Fonte - Ribeiro e Walter (2008). Organização das autoras.

Aplicou-se o procedimento de pós-classificação disponível no Spring para maior homogeneidade nas classes a partir do reagrupamento de células que ocorrem em menor número com as suas semelhantes. Posteriormente, os arquivos em formato raster foram convertidos para vetor no ArcGis, 
onde procedeu-se com a correção dos dados, polígono a polígono, conforme informações observadas em campo.

O trabalho de campo, realizado em setembro de 2018, com base no mapa de cobertura e uso da terra de 2016, permitiu a validação de 27 pontos amostrais, possibilitanto por sua vez, a inspeção visual dos mapas que já apresentavam índice Kappa de 77,31\% (ano de 1985), 86,55\% (ano de 1995), $87,45 \%$ (ano de 2005) e 56,69\% (ano de 2016) e a correção das confusões de classicação.

\section{Análise da paisagem}

Para quantificação da estrutura da paisagem e análise dos seus padrões espaciais, as métricas de paisagem foram calculadas no Patch Analyst, uma extensão desenvolvida por Rempel et al. (2012) para o software ArcGis. Ressalta-se que as métricas mensuram os polígonos das classes dos mapas de cobertura e uso da terra, o que permite quantificar a composição da paisagem. Esta também é analisada conforme sua distribuição na paisagem, tendo como base conceitos de mancha, corredor e matriz. Dessa forma, com a análise dos anos 1985, 1995 e 2005 e 2016 busca-se interpretar padrões espaço-temporais de uso que revelem caminhos para planejamento e gestão das paisagens.

No presente trabalho utilizaram-se as seguintes métricas: número de manchas (NP); área das manchas em hectares e percentagem (CA e PLAND); soma de áreas centrais (TCA) em hectare; distância euclidiana média ao vizinho mais próximo (ENN-MN) em metros, como descritas no Quadro 2. Convém salientar, que as métricas selecionadas se destacam em estudos realizados para o Cerrado goiano por vários autores (CARNEIRO, 2012; SIQUEIRA, 2012; FARIA, 2011; PONCIANO, 2017; MASCARENHAS e FARIA, 2018).

Quadro 2 - Descrição das métricas da paisagem selecionadas.

\begin{tabular}{|c|l|l|}
\hline Métrica & Escala & \multicolumn{1}{|c|}{ Descrição } \\
\hline CA & Classe & $\begin{array}{l}\text { Métrica de área central, corresponde a soma da área (ha) de todos os } \\
\text { fragmentos da classe. }\end{array}$ \\
\hline PLAND & Classe & $\begin{array}{l}\text { Métrica de área central, corresponde a área total (CA) da classe na } \\
\text { paisagem em porcentagem. }\end{array}$ \\
\hline NP & $\begin{array}{l}\text { Classe e } \\
\text { paisagem }\end{array}$ & $\begin{array}{l}\text { Métrica de número de manchas (fragmentos) existentes na classe } \\
\text { correspondente. }\end{array}$ \\
\hline TCA & $\begin{array}{l}\text { Classe } \\
\text { paisagem }\end{array}$ & $\begin{array}{l}\text { Métrica de área central. A área central total (TCA) nos níveis de classe e } \\
\text { paisagem corresponde a soma das áreas centrais de cada mancha, em } \\
\text { hectare. }\end{array}$ \\
\hline ENN-MN & Classe & $\begin{array}{l}\text { Distância Euclidiana média do vizinho mais próximo é a distância média } \\
\text { entre todos fragmentos até o fragmento vizinho mais próximo da mesma } \\
\text { classe, borda a borda em linha reta e em metros. }\end{array}$ \\
\hline
\end{tabular}

Fonte - MCGARIGAL; MARKS, 1995. Organização das autoras.

\section{RESULTADOS E DISCUSSÃO}

A dinâmica de ocupação histórica da bacia, obtida pelos mapeamentos de cobertura e uso da terra (Figura 2), indica que o processo de ocupação já estava estabelecido no primeiro ano avaliado (1985) com grandes manchas existentes na porção centro leste, que como o mapeamento indica são ampliadas para a porção do sul ao longo dos anos avaliados. Esse processo de ocupação é prioriamente desenvolvido em áreas com topografia plana (0 a 12\%) que em função dos atributos geoambientais não apresentam nenhuma ou pouca propensão à ocorrência de processos erosivos, entretanto, sabe-se que o manejo pode impactar o solo dessas áreas. 
Figura 2 - Cobertura e uso da terra na BHRT (1985 - 2016).

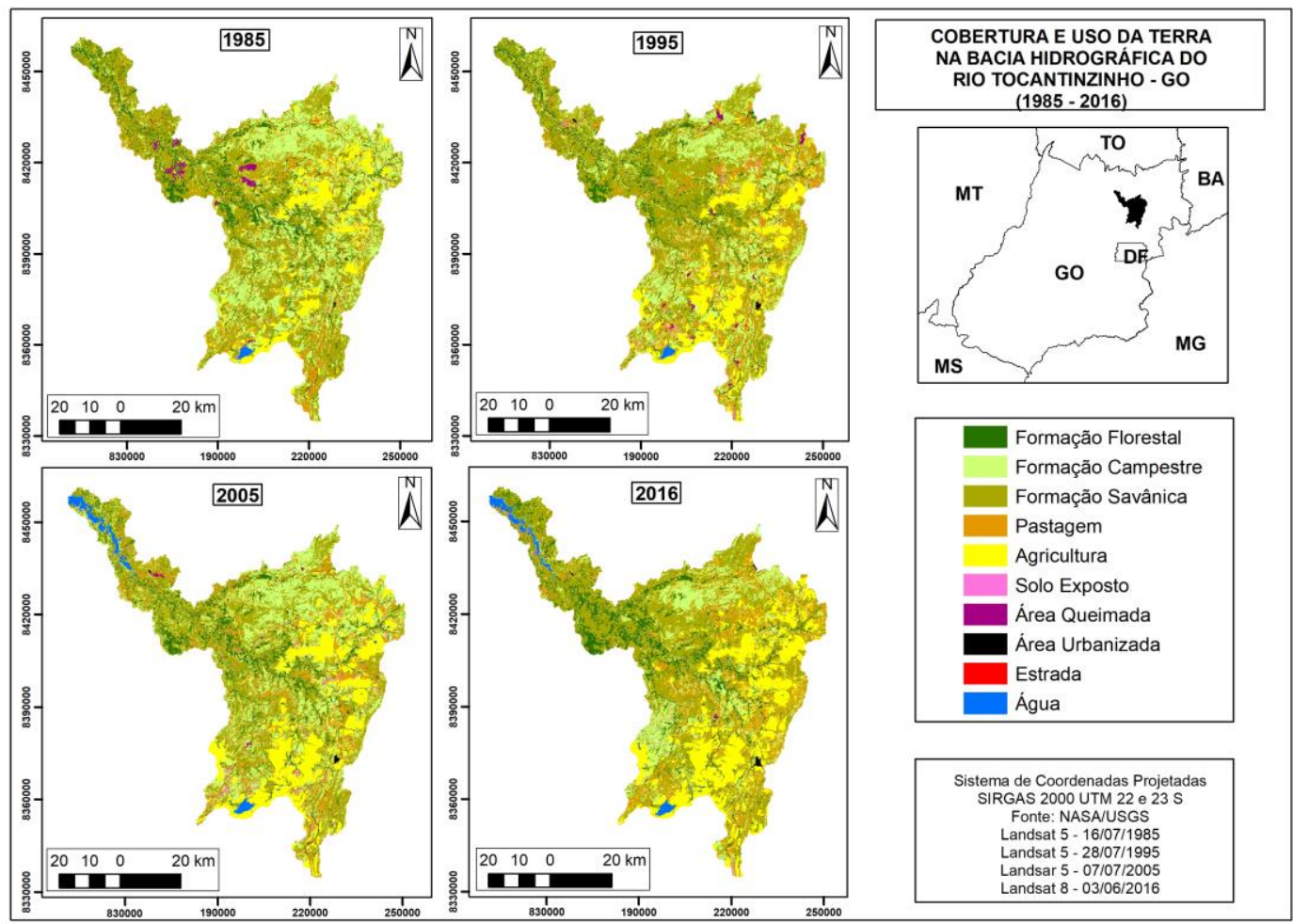

Fonte - Elaboração das autoras.

Embora as atividades agropecuárias estejam estabelecidas na área, a cobertura vegetal predomina na BHRT, principalmente na porção noroeste, onde parte do rio Tocantinzinho é represada compondo - Lago Serra da Mesa. A classe de formação savânica destacou-se dentre as classes de cobertura com maior percentual de área.

O padrão de ocupação das áreas de pastagens e de agricultura é semelhante ao verificado por Faria e Castro (2007), Ponciano; Rodrigues e Faria (2019) e por Trindade et al. (2018) em avaliações dos processos de ocupação em outras regiões no estado de Goiás. As mudanças relacionadas à composição e configuração dessas classes evidenciou aumento de área (Figura 3), em detrimento a redução da área da cobertura vegetal, sobre áreas de relevo plano a suave ondulado, principalmente para classe de agricultura.

Figura 3 - Evolução da dinâmica de ocupação da bacia por meio da Métrica PLAND.

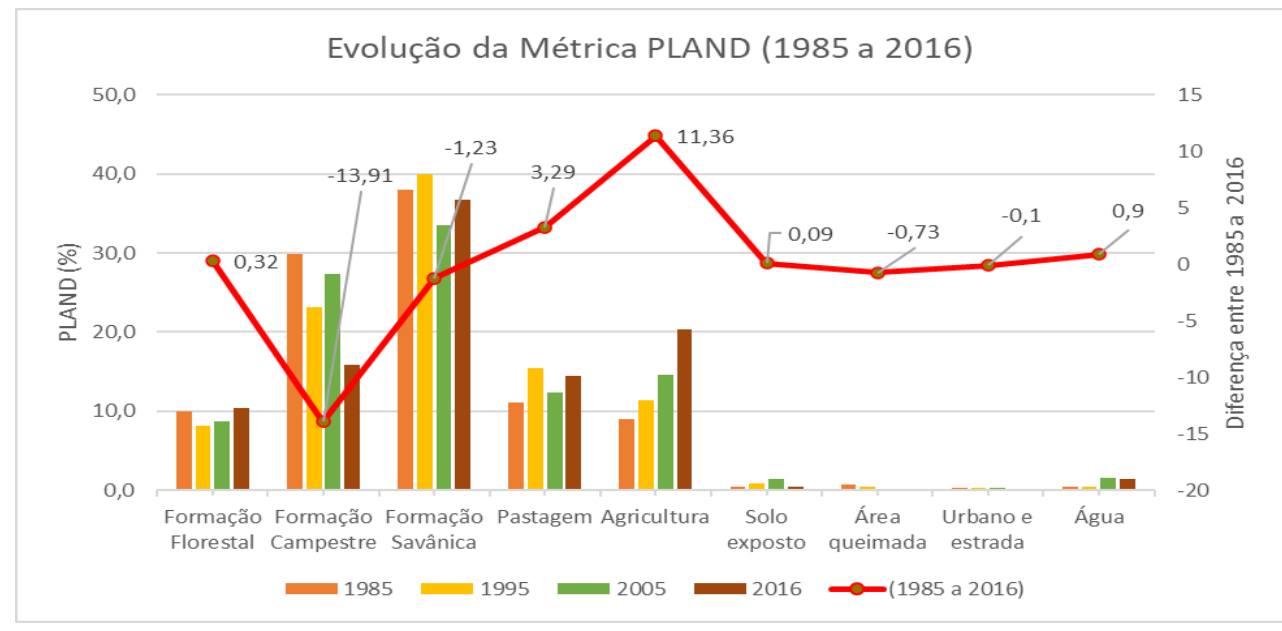

Fonte - Dados da pesquisa. 
A formação campestre foi a formação que mais perdeu área na BHRT, no período analisado. Essa redução foi de 6,73\% entre 1985 e 1995. Entre 1985 e 1995 o uso antrópico predominante na BHRT era a pastagem. Entre 1985 e 1995 a formação florestal diminuiu 1,87\%, sendo substituída por áreas de pastagem. Dessa porcentagem, parte classificada como formação florestal em 1985 passou por processo de antropização e interferência em sua forma estrutural, sendo identificada em 1995 como formação savânica, que nesse intervalo (1985 - 1995) aumentou 1,97\%. Esse aumento na área da formação savânica também se deve a conversão de áreas de formação campestre em formação savânica. Esse padrão de alteração na forma das formações também foi observado por Faria (2011) em bacia hidrográfica na porção sudeste do estado de Goiás.

Entre 1985 e 1995, a formação campestre também foi convertida para área de pastagem, agricultura e solo exposto. A pastagem e a agricultura aumentaram juntas $6,59 \%$. O solo exposto aumentou $0,42 \%$.

Há que se ressaltar que, mesmo representando uma pequena porcentagem e com sua redução, a área de queimada no ano de 1985 foi representativa $(3.916,27 \mathrm{ha})$, o que pode indicar, além da ocorrência natural intrínseca ao Cerrado, o uso indiscriminado dessa estratégia para abertura de novas áreas agrícolas e de pasto.

Entre 1995 e 2005 houve aumento na área da formação florestal (0,6\%) e da formação campestre (4,33\%). Áreas de pastagem e formação savânica em 1995 correspondiam em 2005 a áreas de formação florestal. Áreas de formação savânica em 1995 passaram em 2005 para formação campestre. Nesse período, a formação savânica foi reduzida em $6,44 \%$. Essa redução se deve a uma conversão para áreas de pastagem, para a classe água e para áreas de formação campestre. Ressalta-se que a área da classe água aumentou 1,17\% em relação ao ano de 1995, o que se deve ao represamento de parte do rio Tocantinzinho para abastecer a usina hidrelétrica de Serra da Mesa, inaugurada em 1998.

Nesse período, área agrícola aumentou 3,29\%, representando avanço sobre áreas de formação campestre, formação savânica, pastagem e áreas queimadas. A área da pastagem diminuiu 3,11\%, em função da conversão para áreas de agricultura e solo exposto. $O$ abandono de pastos pode também justificar essa redução, visto que 26.640,56 ha de pastagem em 1995 passaram em 2005 para formação campestre. Essa conversão de áreas antrópicas em formações vegetacionais está associado ao abandono do uso antrópico e ao processo de revegetação natural e espontâneo do cerrado.

A área de solo exposto sofreu acréscimo de $0,55 \%$, aumento que parece irrelevante, mas pode estar relacionado à abertura de novas áreas destinadas a usos antrópicos. Áreas das classes urbana, estrada e de queimada também aumentaram no período entre 1995 e 2005.

Entre 2005 e 2016, a formação campestre, teve sua área reduzida 11,51\%; a formação florestal aumentou $1,59 \%$, referindo principalmente a conversão de áreas de formação savânica para formação florestal, relacionado ao adensamento vegetacional, possível de ocorrência, como indicado por Pinheiro (2016). O decréscimo de $11,51 \%$ na área da formação campestre relaciona-se à áreas que em 2005 correspondiam a formação campestre, mas que em 2016 passaram para pastagem e foram adensadas para aspectos vegetacionais da formação savânica, que consequentemente teve aumentou 3,24\% sobre áreas que em 2005 eram de formação campestre e pastagem.

Nesse intervalo, a pastagem aumentou 2,13\%, indicando a conversão de áreas de formação savânica e campestre em pastagem, mas essa classe perdeu sua expressividade e predominância para classe de agricultura. Áreas que em 2005 correspondiam a formação campestre, savânica e pastagem passaram em 2016 para áreas agrícolas, determinando um aumento de 5,76\% na área da classe de agricultura. 
Ao longo de todo o período avaliado (Figura 3) verifica-se que as áreas da formação campestre é a que acumula perda líquida de vegetação de 13,91\%; as formações savânicas também foram convertidas, enquando as formações florestais apresentam crescimento. $O$ crescimento dessa classe ao longo desse período pode estar associado a revegetação ou crescimento de área de preservação permanente. Tal comportamento já foi avaliado em outros ambientes de cerrado (PONCIANO et al., 2015). O aumento das classes de agricultura e de pastagem, assim como da classe água dimensionam os atores desenvolvimentista em atuação na bacia.

De acordo com Pivello (2005), o alto grau de fragmentação e o isolamento desses fragmentos remanescentes em meio à grandes monoculturas, árvores exóticas ou em meio aos pastos caracterizam o Cerrado, e há que se destacar que essa fragmentação de habitats é uma das mais comuns consequências da atual dinâmica de uso da terra e representa grave ameaça a biodiversidade como apontam Tabarelli e Gascon (2005).

Nesse contexto, uma métrica importante para análise da estrutura da paisagem na BHRT é referente ao Número de Manchas (NP) (Figura 4), que expressa pela evolução crescente do número de manchas a ocorrência de processos de fragmentação e pode indicar união ou extinção de fragmentos de mesma classe em virtude de uma evolução decrescente (MCGARIGAL e MARKS, 1995).

Figura 4 - Número de manchas (NP) da cobertura vegetal na BHRT.

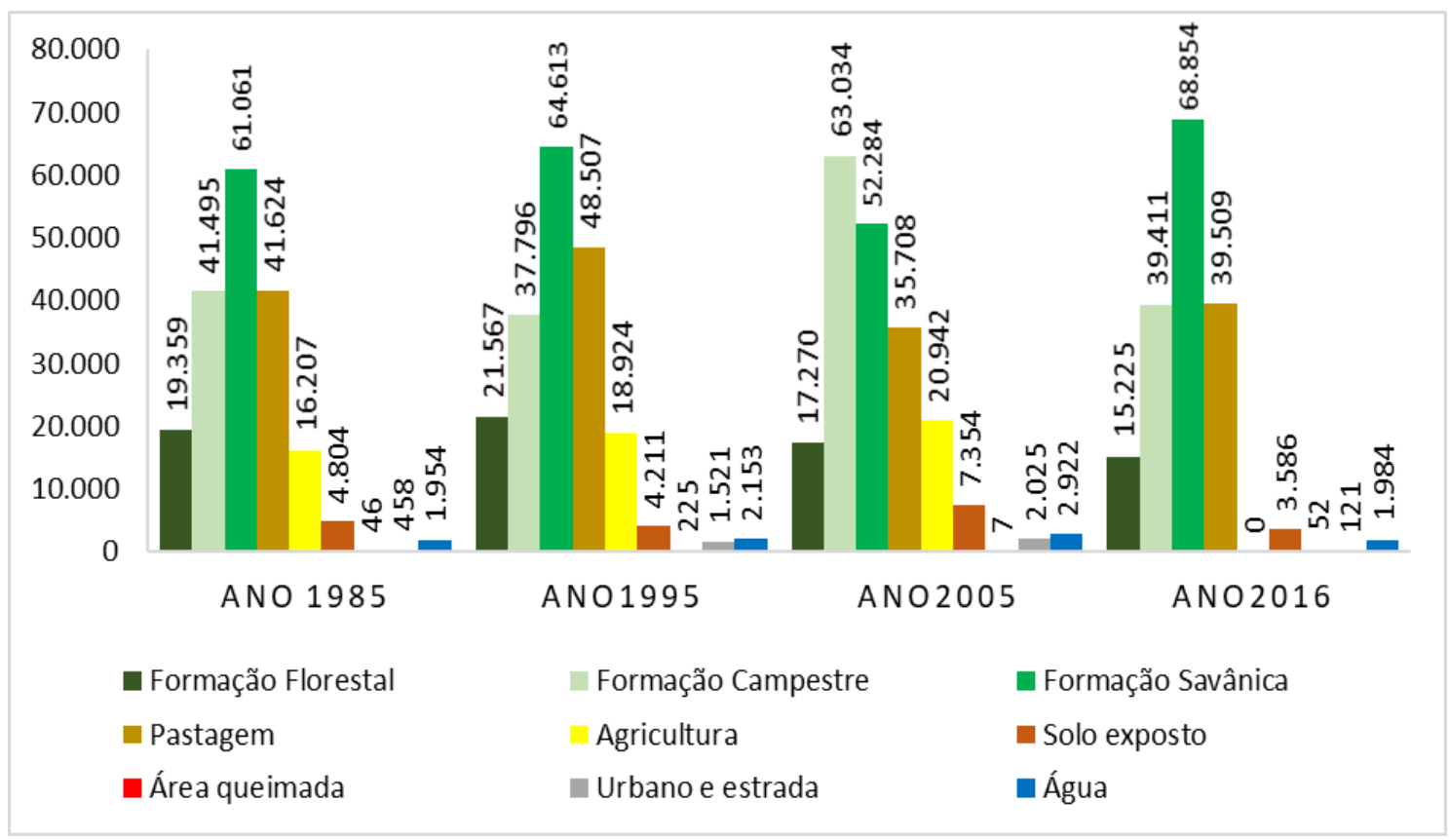

Fonte - Organização das autoras.

A análise da métrica NP indica duas dinâmicas na escala temporal de 1985 a 2016: uma primeira, entre 1985 e 2005; e uma segunda, entre 2005 e 2016. Entre 1985 e 2005, o acréscimo no número de manchas de vegetação permitiu identificar a ocorrência de processos de fragmentação, entre 2005 e 2016 houve redução no número dos fragmentos. Em 1985, a cobertura vegetal apresentava 123.900 fragmentos, passando para 125.971 e para 134.593 fragmentos nos anos 1995 e 2005, respectivamente. Já entre 2005 e 2016 houve uma redução de 9.087 fragmentos.

Por outro lado, o número de fragmentos da classe de agricultura aumentou continuamente no período analisado, e para a pastagem, apesar do decréscimo ocorrido entre 1995 e 2005, também há, em termos gerais, aumento no número de fragmentos. Considerando os usos (agricultura, pastagem, solo exposto e área queimada), de modo geral, observa-se que houve aumento no número de fragmentos 
entre 1995 e 1985, que sofrem redução entre 1995 e 2005, mas retomam crescimento entre 2005 e 2016.

Ainda sobre o número de manchas de vegetação, convém ressaltar que mesmo com a redução no número dos fragmentos entre 2005 e 2016, ao analisar especificamente a métrica NP para a formação savânica observa-se aumento no número de fragmentos. A avaliação do processo de fragmentação com base na relação entre número de fragmentos e tamanho médio dos mesmos indica que $86,83 \%$ dos fragmentos da formação savânica, em 2016, apresentavam área inferior a 1 hectare e apenas $0,27 \%$ apresentavam área superior a 100 hectares (Tabela 1).

Tabela 1 - Relação entre tamanho de Fragmentos/Área na BHRT.

\begin{tabular}{|c|c|c|c|c|c|c|c|c|c|c|c|c|}
\hline & \multicolumn{4}{|c|}{ Florestal } & \multicolumn{4}{|c|}{ Campestre } & \multicolumn{4}{|c|}{ Savânica } \\
\hline & \multicolumn{2}{|c|}{1985} & \multicolumn{2}{|c|}{2016} & \multicolumn{2}{|c|}{1985} & \multicolumn{2}{|c|}{2016} & \multicolumn{2}{|c|}{1985} & \multicolumn{2}{|c|}{2016} \\
\hline & NP & $\begin{array}{l}\text { Área } \\
\text { total }\end{array}$ & NP & $\begin{array}{l}\text { Área } \\
\text { total }\end{array}$ & NP & $\begin{array}{l}\text { Área } \\
\text { total }\end{array}$ & NP & $\begin{array}{l}\text { Área } \\
\text { total }\end{array}$ & NP & $\begin{array}{l}\text { Área } \\
\text { total }\end{array}$ & NP & $\begin{array}{l}\text { Área } \\
\text { total }\end{array}$ \\
\hline$<1$ & 15.094 & 3.539 & 11.454 & 2.747 & 34.351 & 7.914 & 33.274 & 7.363 & 52.114 & 11.750 & 59.785 & 12.892 \\
\hline 1 a 10 & 3.294 & 10.656 & 2.932 & 9.675 & 5.787 & 17.284 & 5.209 & 15.177 & 7.546 & 21.662 & 7.806 & 22.073 \\
\hline 10 a 50 & 804 & 17.100 & 664 & 14.304 & 969 & 20.952 & 744 & 15.366 & 1.033 & 21.481 & 918 & 18.812 \\
\hline 50 a 100 & 110 & 7.591 & 108 & 7.519 & 163 & 11.487 & 103 & 7.176 & 164 & 11.472 & 160 & 11.220 \\
\hline$>100$ & 57 & 12.806 & 67 & 19.121 & 225 & 96.161 & 81 & 36.972 & 204 & 129.584 & 185 & 124.609 \\
\hline Total & 19.359 & 51.693 & 15.225 & 53.365 & 41.495 & 153.798 & 39.411 & 82.054 & 61.061 & 195.949 & 68.854 & 189.605 \\
\hline
\end{tabular}

Fonte - Organização das autoras.

O predomínio de fragmentos com área inferior a 1 ha em 2016 também foi verificado para as formações florestal e campestre. Tais resultados mostram-se desfavoráveis a sustentabilidade dos fragmentos vegetacionais, visto que, conforme Saunders et al. (1991), quanto menor o tamanho do fragmento, maior o efeito de borda em relação à área central do fragmento e menor a diversidade de habitats. Os pequenos fragmentos apresentam maior interação com a matriz, podendo ter sua totalidade atingida pelos efeitos externos promovendo empobrecimento de espécies (TABARELLI et al., 2004).

Convém ressaltar que, entre 1985 e 2016, para formação campestre houve redução no número de fragmentos para todas as classes de tamanho analisadas e redução de suas áreas, reforçando a proposição de que essa classe foi a que mais sofreu conversão para uso antrópico. Já para formação florestal os dados revelam redução no número de fragmentos com área inferior a 100 ha, o que sugere também a extinção de fragmentos menores, uma vez que a área total dessas classes também foi reduzida. Já o número de fragmentos com área maior que 100 ha tiveram seu total expandido, com aumento na área total, sugerindo fragmentação nessa classe de tamanho. A formação savânica, entre 1985 e 2016, apresentou redução de fragmentos menores que 10 ha, mas apresentaram aumento na área total, indicando fragmentação, e redução da área total e do número de fragmentos das classes de área maior que 10 ha. Este aspecto permite inferir, para classe formação savânica, que foram fragmentos com área superior a 10 ha que mais perderam vegetação nativa.

A área central (TCA) da formação florestal e campestre apresentaram queda entre 1985 e 1995 e acréscimo entre 1995 e 2005 (Figura 5). Entre 2005 e 2016, o total de área central da formação florestal aumentou e da formação campestre diminuiu. Já a formação savânica teve a sua área central ampliada entre 1985 e 1995, reduzida entre 1995 e 2005 e novamente ampliada entre 2005 e 2016. Entre 1985 e 1995 destaca-se o crescimento da área central das classes de pastagem, agricultura e solo exposto, que permite inferir sobre a redução da métrica TCA das formações florestal e campestre nesse período. Entre 1995 e 2005 destaca-se o acréscimo na área central da classe água, relativa ao represamento para a Usina Serra da Mesa que ocasionou a inundação

$\begin{array}{lllll}\text { Caminhos de Geografia } & \text { Uberlândia-MG } & \text { v. 22, n. } 81 & \text { jun./2021 } & \text { p. 74-87 }\end{array}$


predominantemente de áreas de formação savânica, que perderam área total (CA) e consequentemente área nuclear.

Figura 5 - Total de Área Central (TCA, em hectare) da BHRT.

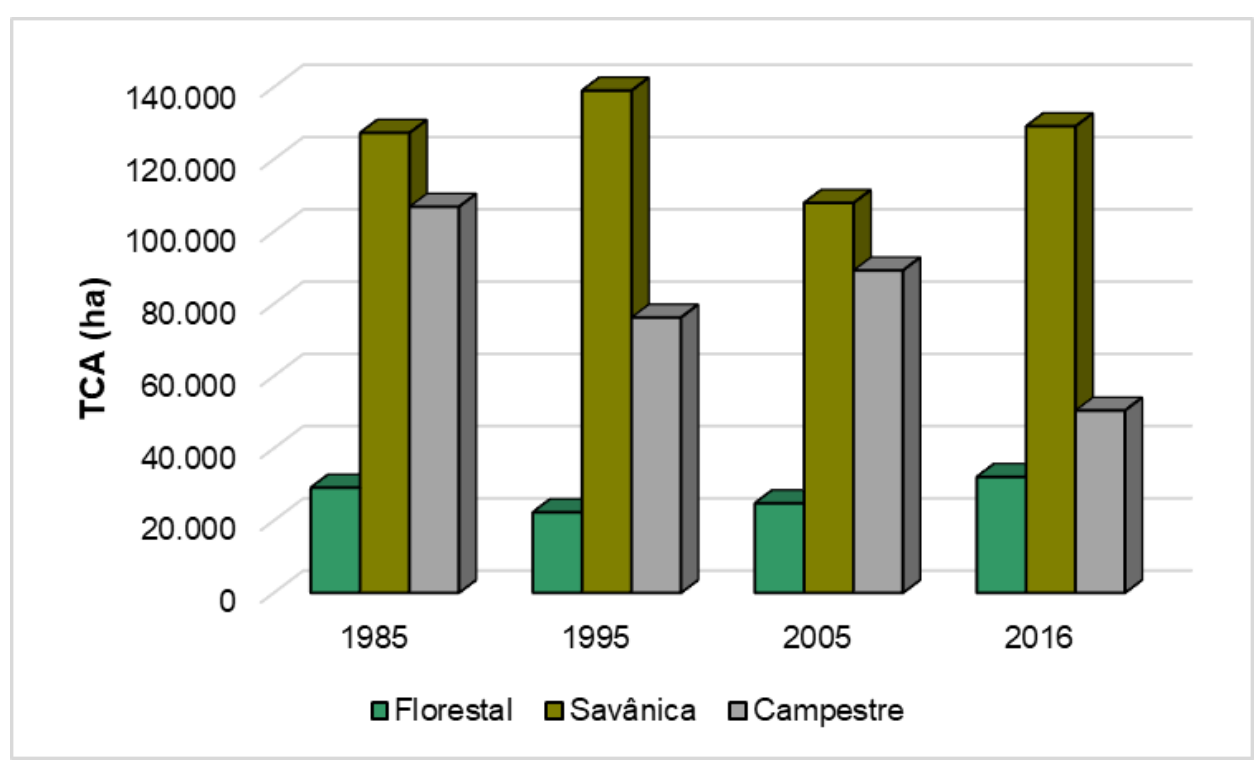

Fonte - Organização das autoras.

A redução do TCA da pastagem e aumento da agricultura, entre 2005 e 2016, reforçam a substituição da pastagem pela agricultura. Nesse período, a redução da área central da formação campestre também merece atenção, podendo indicar redução da qualidade de habitats. Essa formação que apresentou nesse período redução no número de fragmentos e no total de borda, também apresentou redução no total de área nuclear, corroborando para a perda geral de área com extinção de fragmentos.

Remanescentes maiores têm uma área central maior que não é afetada pelo ambiente e mudanças associadas com as bordas. Nesse sentido, quanto maior o tamanho da área nuclear do fragmento maior a qualidade da estrutura dos ecossistemas (SAUNDERS et al., 1991; VALENTE, 2001). Rambaldi e Oliveira (2003) explicam que o número de indivíduos por área é proporcional à qualidade do habitat, bons habitats podem ter maior densidade, mas se sua área diminui, diminui também a abundância populacional de espécies. Mas há que se destacar, conforme salientam Fiszon et al. (2003), que os pequenos fragmentos também se tornam importantes ao conectarem grandes fragmentos, viabilizando o movimento de várias espécies entre manchas maiores.

Os efeitos da interação entre um ecossistema e uma matriz estruturalmente distinta envolvem mudanças nas condições ambientais na área da mancha remanescente; mudanças na abundância e distribuição de espécies; e mudanças na interação das espécies, como predação, competição, herbivoria, dispersão de sementes e polinização biótica (MURCIA, 1995). E, embora fragmentos pequenos possam funcionar como stepping stones, principalmente em áreas próximas a grandes núcleos de biodiversidade (ALMEIDA, 2008), como o PNCV, estas pequenas áreas ficam sujeitas a altas e imensuráveis interferências da matriz antrópica predominante e envolvente.

O processo de invasão de habitats destaca-se como o impacto mais significativo nas bordas dos fragmentos remanescentes de cerrado. Na pesquisa realizada por Mendonça et al. (2015), verificouse que quanto mais próximo da borda, maior a cobertura por gramíneas invasoras e, consequentemente, menor a densidade e riqueza dos sub-arbustos e das gramíneas nativas. Com o avanço da invasão biológica para área central dos remanescentes há ampliação dos efeitos adversos, como o comprometimento das espécies nativas a longo prazo. Os autores sugerem que a prevenção e o controle da expansão de espécies invasoras são questões prioritárias para conservação do cerrado, visto que tais espécies podem alterar o regime de fogo e inibir a regeneração de espécies nativas. 
Nesse contexto, Mendes e Silva (2008) verificaram a suscetibilidade da vegetação do cerrado aos efeitos da matriz antrópica. Em estudo realizado pelos autores no Parque Nacional da Chapada dos Guimarães verificou-se que as áreas de formação campestre (Campo Limpo) tendem a ser mais impactadas pelo efeito de borda, principalmente quando há influência da matriz pastagem sem controle de espécies exóticas.

Convém salientar que o efeito de borda não afeta apenas processos bióticos, mas também processos abióticos em função das relações laterais e funcionais entre os elementos da paisagem (BLASCHKE e LANG, 2009), e estes, por sua vez, podem afetar a composição e a distribuição de espécies em resposta às alterações no habitat causadas, por exemplo, pelo aumento do fluxo de energia (penetração de radiação solar, exposição direta aos ventos, entrada de escoamento superficial) e a entrada de componentes químicos pela borda (PAGLIA et al.,2006).

Redução nas taxas de migração e dispersão de populações de plantas e animais que, em geral, com o tempo sofrem problemas de troca gênica e declínio populacional (RAMBALDI e OLIVEIRA, 2003) são outros efeitos que se relacionam ao isolamento de habitats. Tal isolamento, perceptível com acréscimo da distância média entre fragmentos, pode ser analisado pela métrica ENN_MN.

Avaliando-se a métrica de isolamento pela Distância Euclidiana média do vizinho mais próximo (ENN_MN) verificou-se um aumento para a classe da formação florestal, entre 1985 e 1995 (Figura 6). Entretanto, este acréscimo foi de apenas 4,31 \% para toda bacia. Após 1995 a distância entre as manchas dessa classe manteve-se estável. Para a classe da formação savânica a distância média aumentou entre 1985 e 1995, mas decresceu após 1995. Contrariando os índices observados para a formação florestal e formação savânica, a distância média entre os fragmentos da formação campestre aumentou em 37,3\%, entre 2005 e 2016.

Figura 6 - Distância média euclidiana dos fragmentos de mesma classe mais próximos da BHRT.

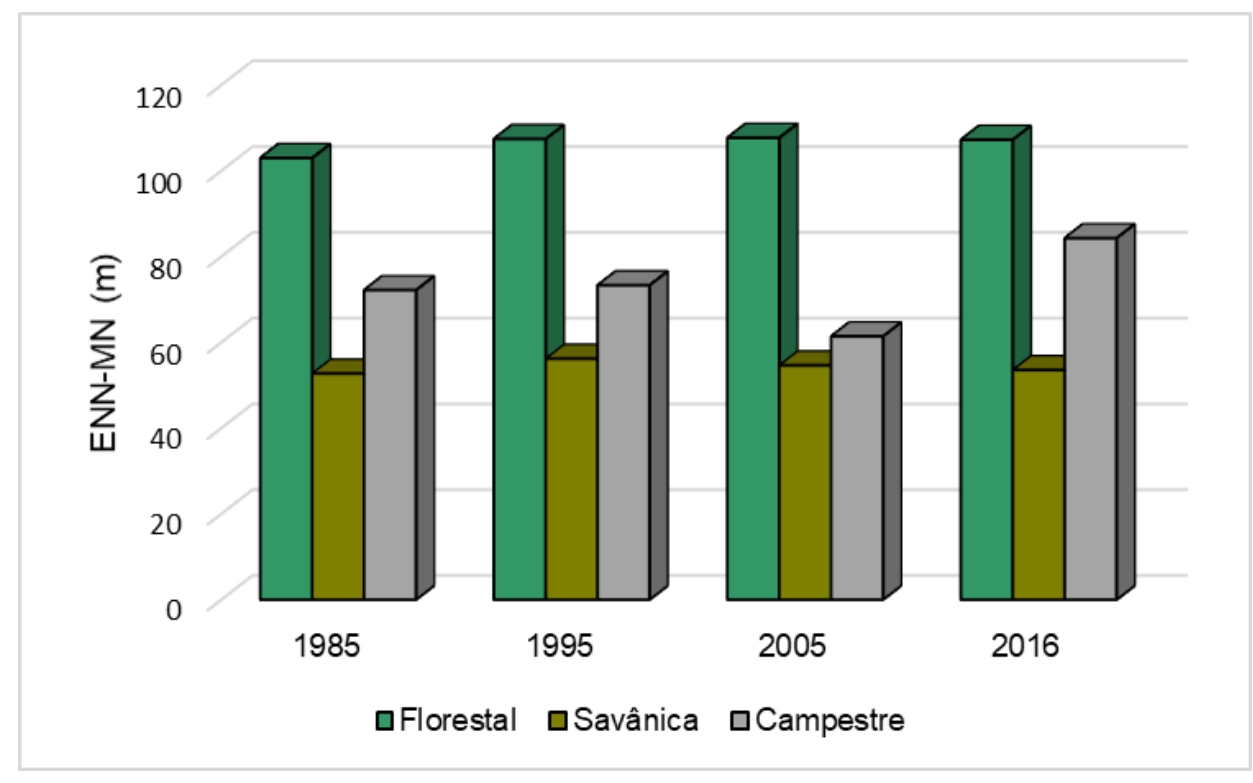

Fonte - Organização das autoras.

Segundo Almeida (2008), distância de até 60 metros são classificadas como de baixo isolamento, entre 60 e 120 metros de médio e entre 120 e 200 metros de elevado isolamento. Nesse contexto, os resultados da métrica ENN_MN para a BHRT, de modo geral, não revelaram comprometimento a capacidade de migração e dispersão de espécies.

Há que se ressaltar que o crescente isolamento observado para os fragmentos da formação campestre demanda atenção, bem como as distâncias entre os fragmentos da formação florestal requer monitoramento, visto que distâncias superiores a 100 metros em uma matriz agrícola podem representar uma barreira completa à dispersão de organismos pequenos, como os invertebrados (MADER, 1984). Como a área de estudo encontra-se em uma categoria de uso sustentável de unidade de conservação (Apa Pouso Alto) e ainda é a zona de amortecimento de um centro de

$\begin{array}{lllll}\text { Caminhos de Geografia } & \text { Uberlândia-MG } & \text { v. 22, n. } 81 & \text { jun./2021 } & \text { p. 74-87 }\end{array}$ 
bioviversidade mundial (PNCV) esse padrão de fragmentação e isolamento de formações do cerrado pode influenciar na conservação das áreas protegidas.

\section{CONCLUSÕES}

O uso das métricas/índices descritores da paisagem instrumentalizado pela abordagem da ecologia da paisagem permitiu avaliar a dinâmica da estrutura da paisagem para um período de 31 anos na BHRT, indicando que mesmo com a ação antrópica, predomina classes de vegetação nativa em detrimento as classes de uso antrópico. Todavia, os dados revelaram crescente perda de área da classe de formação campestre.

Nesse contexto, é possível inferir sobre um processo de conversão ainda inicial com alteração nos padrões de ocupação das classes de agropecuária, pois verificou-se substituição de áreas de pastagem pela agricultura e avanço da pecuária sobre áreas de vegetação. A formação campestre por apresentar predomínio de vegetação herbácea se apresenta como mais atrativa para pastagem e por isso se destaca como escolha inicial para ocupação. Há ainda que se considerar que tal vegetação encontra-se principalmente em áreas de relevo que impõem maior dificuldade de motomecanização, e consequentemente dificultam o avanço da agricultura.

A expansão dos usos antrópicos condiciona aumento da heterogeneidade do mosaico da paisagem da BHRT, a qual pode afetar a permeabilidade da matriz aos fluxos biológicos. Dessa forma, considerando o elevado aumento da área da agricultura, principalmente entre 2005 e 2016, é importante considerar esse processo inicial de mudança para monitorar a fragmentação da formação savânica e dos grandes fragmentos de formação florestal. Com isso, busca-se minimizar impactos nos processos ecológicos em uma área importante para a população goiana que carece dos serviços ecossistêmicos.

Por outro lado, a redução da vegetação campestre também inspira atenção, uma vez que o uso antrópico em áreas de declive acentuado exige maior atenção no manejo para evitar desequilíbrios morfodinâmicos que condicionem origem e evolução de processos erosivos, perda de solo e assoreamento dos cursos d'água. A vegetação campestre, apesar de não suscitar incisciva proteção de leis ambientais como ocorre para formação florestal, possuiu sua importância ecossistêmica que deve ser considerada, inclusive para conectividade da paisagem reduzindo o isolamento.

Portanto, a análise espaço-temporal confirmou as preferências de áreas com características favoráveis ao uso agropecuário intensivo para conversão da vegetação nativa, uma vez que, no período analisado, as áreas em que a vegetação persiste se relacionam, principalmente, às áreas de declives mais acentuados. Para a BHRT, que integra áreas prioritárias para conservação, a pesquisa tem sua relevância ao somar com outras pesquisas que discutem a priorização pelo Poder Público de modelos de desenvolvimento baseados na conservação, optando por fomentar o ecoturismo e modelos agrícolas compatíveis com as potencialidades e limitações da área, em oposição as atividades que possam impactar ainda mais a estrutura das paisagens.

\section{AGRADECIMENTOS}

Agradecimentos à Coordenação de Aperfeiçoamento de Pessoal de Nível Superior - Brasil (CAPES) Código de Financiamento 001 à primeira autora, em função de concessão de bolsa de mestrado.

\section{REFERÊNCIAS}

ALMEIDA, C. G. Análise espacial dos fragmentos florestais na área do Parque Nacional dos Campos Gerais, Paraná. 2008. 72 f. Dissertação (Mestrado em Gestão do Território) - Universidade Estadual de Ponta Grossa, Ponta Grossa, 2008.

CARNEIRO, G. T. Processo de fragmentação e caracterização dos remanescentes de Cerrado: análise ecológica da paisagem da bacia do Rio dos Peixes (GO). 2012. 136f. Tese (Doutorado em Ciências Ambientais) - Instituto de Estudos Sócio-Ambientais, Universidade Federal de Goiás, Goiânia, 2012. 
FARIA, K. M. S. de; CASTRO, S. S. Uso da terra e sua relação com os remanescentes de cerrado na alta bacia do rio Araguaia (GO, MT E MS). Geografia (Rio Claro), v. 32, p. 657-668. 2007.

FARIA, K. M. S. Paisagens Fragmentadas e Viabilidades de Recuperação para a sub-bacia do rio Claro (GO). 2011. 194f. Tese (Doutorado em Geografia) - Universidade Federal de Goiás, Goiânia, 2011.

FISZON, J. T. et al. Causas Antrópicas. In: RAMBALDI, D.; OLIVEIRA, D. A. S. (Orgs.). Fragmentação de ecossistemas: causas, efeitos sobre a biodiversidade e recomendações de políticas públicas. Brasília: MMA/SBF, 2003. p. 66-99.

FORMAN, R. T. T. Some general principles of landscape and regional ecology. Landscape Ecology, Amsterdam, v. 10 n. 3 p. 133-142, 1995. https://doi.org/10.1007/BF00133027

FORMAN, T. T. R.; GORDON, M. Landscape Ecology. New York: Wiley, 1986. 619p.

FORMAN, T. T. R.; GORDON, M. Patches and structural components for a lands ecology. Bioscience, v. 31, n. 10, p. 733-740, 1981. https://doi.org/10.2307/1308780

FOSTER, D.; SWANSON, F.; ABER, J.; BURKE, I.; BROKAW, N.; TILMAN, D.; KNAPP, A. The importance of land-use legacies to ecology and conservation. BioScience, v. 53, p. 77-88, 2003. https://doi.org/10.1641/0006-3568(2003)053[0077:TIOLUL]2.0.CO;2

icacoes/Documents/Synergism.pdf>. Acesso em 29 set. 2018.

LANG, S; BLASCHKE, T. Análise da paisagem com SIG. Tradução Hermann Kux. São Paulo: Oficina de Textos, 2009.

MADER, H.J. Animal habitat isolation by roads and agricultural fields. Biological Conservation. V. 29, Issue 1, 1984, p.81-96. Disponivel em: www.sciencedirect.com/science/article/pii/0006320784900156. Acesso em 25 de maio de 2020. https://doi.org/10.1016/0006-3207(84)90015-6

MAPEAMENTO ANUAL DA COBERTURA E USO DO SOLO NO BRASIL (MAPBIOMAS). Projeto MapBiomas - Coleção 4.0 da Série Anual de Mapas de Cobertura e Uso de Solo do Brasil. 2019. Disponível em: <http://plataforma.mapbiomas.org/map\#coverage>. Acesso em: 15 out. 2019.

MASCARENHAS, H. G. B.; FARIA, K. M. de. Dinâmica da paisagem e relações com o uso do solo e fragmentação da cobertura vegetal no município de Flores de Goiás (GO) entre 1985 e 2017. Élisée, Rev. Geo. UEG, Porangatu, v.7, n.2, jul. / dez. 2018.

MCGARIGAL, K.; MARKS, B. J. FRASTATS: spatial pattern analysis program for quantifying landscape structure. USDA For. Serv. Gen. Tech. Rep, 1995. Disponível em:< https://www.fs.usda.gov/treesearch/pubs/3064>. Acesso em 8 jun. 2018. https://doi.org/10.2737/PNWGTR-351

MENDES, J. D.; SILVA, N. M. Avaliação do efeito de borda em fragmentos de cerrado por meio de métricas de paisagem, no Parque Nacional de Chapada dos Guimarães, Mato Grosso, Brasil. IX Simpósio Nacional Cerrado. 2008. Anais... Parlamundi, Brasília, DF. 2008.

MENDONÇA, A. H.; RUSSOB, C.; MELOC, A. C. G.; DURIGANC, G. Edge effects in savanna fragments: a case study in the cerrado. Plant Ecology \& Diversity, v. 8, n. 4, p. 493-503, 2015. https://doi.org/10.1080/17550874.2015.1014068

MMA. Ministério do Meio Ambiente. Mapeamento do Uso e Cobertura do Cerrado: Projeto TerraClass Cerrado 2013. Brasília: MMA/SBF, 67 p., 2015.

MURCIA, C. Edge effects in fragmented forests: implications for conservation. Trends in Ecology and Evolution, v. 10 n. 2 p. 58-62. 1995. https://doi.org/10.1016/S0169-5347(00)88977-6

PAGLIA, A. P.; FERNANDEZ, F. A. S.; DE MARCO, P. Efeitos da fragmentação de habitats: quantas espécies, quantas populações, quantos indivíduos, e serão eles suficientes? In: ROCHA, C. F. D.; BERGALLO, H. G.; SLUYS, M. V.; ALVES, M. A. S. (Orgs.). Biologia da Conservação: Essências. São Carlos: Rima Editora, 2006.

PINHEIRO, L. F. S. Diversidade florística e morfoanatômica de comunidades não arbóreas de cerrado sensu stricto frente ao adensamento vegetacional na ausência de fogo. 2016. 87f. (Mestrado em Biociências) - Universidade Estadual Paulista. Assis, 2016. 
PIVELLO, V. R. Manejo de Fragmentos de Cerrado: princípios para a conservação da biodiversidade. In: Cerrado. Brasília: MMA/SBF. 2005.

PONCIANO, A. T. Dinâmica da estrutura da paisagem na microrregião do vão do Paranã (GO). 2017. 69 f. Dissertação (Mestrado em Ciências Ambientais) - Universidade Federal de Goiás. Goiânia, 2017. https://doi.org/10.5216/ag.v13i2.54857

PONCIANO, T. A.; RODRIGUES, H. S. M. de C.; FARIA, K. M. S. de. Abordagem morfopedológica para avaliação histórica da estrutura da paisagem no Vão do Paranã (GO). Ateliê Geográfico, 13(2), 111-127. 2019.

RAMBALDI, D. M., OLIVEIRA, D. A. S. de (Org.). Fragmentação de ecossistemas: causas, efeitos sobre a biodiversidade e recomendações de políticas públicas. Brasília: MMA/SBF, 2003.

RIBEIRO, H. de F.; FARIA, K. M. S. de; CEZARE, C. H. G. Dinâmica espaço-temporal do desmatamento nos Territórios da Cidadania no nordeste goiano. Revista Brasileira de Geografia Física, Recife, v. 12, n. 3, 2019. https://doi.org/10.26848/rbgf.v12.3.p1180-1196

RIBEIRO, J.F.; WALTER, B.M.T. As principais fitofisionomias do Bioma Cerrado. In: SANO, S.M.; ALMEIDA, S.P de; RIBEIRO, J. F. Cerrado: ecologia e flora. Brasília: Embrapa Informação Tecnológica, 2008. p. 153-212.

SANTOS, J. G. R. dos; CASTRO, S. S. de. Influência do meio físico na produção dos assentamentos rurais das Regiões do Sul e do Nordeste Goiano. Soc. \& Nat., Uberlândia, v. 28, n. 1, p. 95-116, jan./abr.2016. https://doi.org/10.1590/1982-451320160107

SAUNDERS, D. A.; HOBBS, R. J.; MARQUES, C. R. Biological consequences of ecosystem fragmentation: a reviem. Biological Conservation, v.5, p. 18-32. 1991. https://doi.org/10.1111/i.1523$\underline{1739.1991 . t b 00384 . x}$

SIQUEIRA, M. N. Avaliação geoecológica do processo de fragmentação dos remanescentes do Cerrado na sub-bacia do Rio das Graças (MT). 2012. 136f. Dissertação (Mestrado em Geografia) Instituto de Estudos Sócio-Ambientais, Universidade Federal de Goiás, Goiânia, 2012. https://doi.org/10.1590/S1982-45132013000300009

SIQUEIRA, M. N; CASTRO, S. S. de; FARIA, K. M. S de. Geografia e Ecologia da Paisagem: pontos para discussão. Sociedade \& Natureza, Uberlândia, v. 25, n. 3, p. 557-566, set/dez 2013.

TABARELLI, M.; GASCON, C. Lições da pesquisa sobre fragmentação: aperfeiçoando políticas e diretrizes de manejo para a conservação da biodiversidade. Megadiversidade, [S.I.], v. 1, n.1, p.181188, jul. 2005.

TABARELLI, M.; SILVA, J. M. C. da; GASCON, C. Forest fragmentation, synergisms and the impoverishment of neotropical forests. Biodiversity and Conservation, v. 13, n. 7, p. 1419-1425, 2004. Disponível em: <https://www.conservation.org/global/brasil/publ. https://doi.org/10.1023/B:BIOC.0000019398.36045.1b

TRINDADE, S. P.; FARIA, K. M. S. de; CASTRO, S. S. de. Análise da expansão canavieira e as mudanças de uso do solo no sudoeste goiano de 1985 a 2016. Boletim Goiano de Geografia, Goiânia, v. 38, n. 3, p. 569-590, set./dez. 2018. https://doi.org/10.5216/bgg.v38i3.56359

VALENTE, R. de O. A. Análise da estrutura da paisagem na bacia do Rio Corumbataí, SP. 2001. 162f. Dissertação (Mestrado em Recursos Florestais) - Escola Superior de Agricultura "Luiz de Queiroz", Universidade de São Paulo, Piracanjuba, 2001.

Recebido em: 01/06/2020

Aceito para publicação em: 20/11/2020 